\title{
Viscosity approximation method with Meir-Keeler contractions for common zero of accretive operators in Banach spaces
}

Jong Kyu Kim ${ }^{1 *}$ and Truong Minh Tuyen ${ }^{2}$

\section{"Correspondence:}

jongkyuk@kyungnam.ac.kr

'Department of Mathematics

Education, Kyungnam University,

Changwon, Gyeongnam 631-701

Korea

Full list of author information is

available at the end of the article

\begin{abstract}
The purpose of this paper is to introduce a new iteration by the combination of the viscosity approximation with Meir-Keeler contractions and proximal point algorithm for finding common zeros of a finite family of accretive operators in a Banach space with a uniformly Gâteaux differentiable norm. The results of this paper improve and extend corresponding well-known results by many others.
\end{abstract}

MSC: 47H06; 47H09; 47H10;47J25

Keywords: accretive operators; prox-Tikhonov method; Meir-Keeler contraction; common zero of accretive operator

\section{Introduction}

Let $E$ be a real Banach space and let $J$ be the normalized duality mapping from $E$ into $2^{E^{*}}$ given by

$$
J(x)=\left\{f \in E^{*}:\langle x, f\rangle=\|x\|^{2}=\|f\|^{2}\right\}, \quad \forall x \in E,
$$

where $E^{*}$ denotes the dual space of $E$ and $\langle\cdot, \cdot\rangle$ denotes the generalized duality pairing. It is well known that if $E^{*}$ is strictly convex then $J$ is single-valued. In the sequel, we denote the single-valued normalized duality mapping by $j$. For an operator $A: E \rightarrow 2^{E}$, we define its domain, range, and graph as follows:

$$
\begin{aligned}
& D(A)=\{x \in E: A x \neq \emptyset\}, \\
& R(A)=\bigcup\{A z: z \in D(A)\},
\end{aligned}
$$

and

$$
G(T)=\{(x, y) \in E \times E: x \in D(A), y \in A x\}
$$

respectively. The inverse $A^{-1}$ of $A$ is defined by

$$
x \in A^{-1} y, \quad \text { if and only if } \quad y \in A x .
$$

\section{Springer}

(0) 2015 Kim and Tuyen; licensee Springer. This is an Open Access article distributed under the terms of the Creative Commons Attribution License (http://creativecommons.org/licenses/by/4.0), which permits unrestricted use, distribution, and reproduction in any medium, provided the original work is properly credited. 
An operator $A$ is said to be accretive if, for each $x, y \in D(A)$, there exists $j(x-y) \in J(x-y)$ such that

$$
\langle u-v, j(x-y)\rangle \geq 0,
$$

for all $u \in A x$ and $v \in A y$. We denote by $I$ the identity operator on $E$. An accretive operator $A$ is said to be maximal accretive if there is no proper accretive extension of $A$ and $A$ is said to be $m$-accretive if $R(I+\lambda A)=E$, for all $\lambda>0$. If $A$ is $m$-accretive, then it is maximal, but generally, the converse is not true. If $A$ is accretive, then we can define, for each $\lambda>0$, a nonexpansive single-valued mapping $J_{\lambda}^{A}: R(I+\lambda A) \rightarrow D(A)$ by

$$
J_{\lambda}^{A}=(I+\lambda A)^{-1}
$$

It is called the resolvent of $A$ which is denoted by $J^{A}$ when $\lambda=1$.

Let $A: E \rightarrow 2^{E}$ be an $m$-accretive operator. It is well known that many problems in nonlinear analysis and optimization can be formulated as the problem: Find $x \in E$ such that

$$
0 \in A(x)
$$

One popular method of solving the equation $0 \in A(x)$, where $A$ is a maximal monotone operator in a Hilbert space $H$, is the proximal point algorithm. The proximal point algorithm generates, for any starting point $x_{0}=x \in E$, a sequence $\left\{x_{n}\right\}$ by the rule

$$
x_{n+1}=J_{r_{n}}^{A}\left(x_{n}\right) \text {, }
$$

for all $n \in \mathbb{N}$, where $\left\{r_{n}\right\}$ is a regularization sequence of positive real numbers, $J_{r_{n}}^{A}=(I+$ $\left.r_{n} A\right)^{-1}$ is the resolvent of $A$, and $\mathbb{N}$ is the set of all natural numbers. Some of them deal with the weak convergence theorem of the sequence $\left\{x_{n}\right\}$ generated by (1.1) and others proved strong convergence theorems by imposing assumptions on $A$.

Note that algorithm (1.1) can be rewritten as

$$
x_{n+1}-x_{n}+r_{n} A\left(x_{n+1}\right) \ni 0 \text {, }
$$

for all $n \in \mathbb{N}$. This algorithm was first introduced by Martinet [1]. If $\psi: H \rightarrow \mathbb{R} \cup\{\infty\}$ is proper lower semicontinuous convex function, then the algorithm reduces to

$$
x_{n+1}=\underset{y \in H}{\operatorname{argmin}}\left\{\psi(y)+\frac{1}{2 r_{n}}\left\|x_{n}-y\right\|^{2}\right\},
$$

for all $n \in \mathbb{N}$. Moreover, Rockafellar [2] has given a more practical method which is an inexact variant of the method:

$$
x_{n}+e_{n} \ni x_{n+1}+r_{n} A x_{n+1}
$$

for all $n \in \mathbb{N}$, where $\left\{e_{n}\right\}$ is regarded as an error sequence and $\left\{r_{n}\right\}$ is a sequence of positive regularization parameters. Note that the algorithm (1.3) can be rewritten as

$$
x_{n+1}=J_{r_{n}}^{A}\left(x_{n}+e_{n}\right)
$$


for all $n \in \mathbb{N}$. This method is called inexact proximal point algorithm. It was shown in Rockafellar [2] that if $e_{n} \rightarrow 0$ quickly enough such that $\sum_{n=1}^{\infty}\left\|e_{n}\right\|<\infty$, then $x_{n} \rightarrow z \in H$ with $0 \in A z$.

Further, Rockafellar [2] posed the open question of whether the sequence generated by (1.1) converges strongly or not. In 1991, Güler [3] gave an example showing that Rockafellar's proximal point algorithm does not converge strongly.

An example of the authors, Bauschke et al. [4] also showed that the proximal algorithm only converges weakly but not strongly.

When $A$ is maximal monotone in a Hilbert space $H$, Lehdili and Moudafi [5] obtained the convergence of the sequence $\left\{x_{n}\right\}$ generated by the algorithm

$$
x_{n+1}=J_{r_{n}}^{A_{n}}\left(x_{n}\right) \text {, }
$$

where $A_{n}=\mu_{n} I+A, \mu>0$ is viewed as a Tikhonov regularization of $A$. Next, in 2006, $\mathrm{Xu}$ [6] and in 2009, Song and Yang [7] used the technique of nonexpansive mappings to get convergence theorems for $\left\{x_{n}\right\}$ defined by the perturbed version of algorithm (1.4) in the form

$$
x_{n+1}=J_{r_{n}}^{A}\left(t_{n} u+\left(1-t_{n}\right) x_{n}+e_{n}\right) .
$$

Note that algorithm (1.6) can be rewritten as

$$
r_{n} A\left(x_{n+1}\right)+x_{n+1} \ni t_{n} u+\left(1-t_{n}\right) x_{n}+e_{n}, \quad n \geq 0 .
$$

In [8], Tuyen was studied an extension the results of Xu [6], when $A$ is an $m$-accretive operator in a uniformly smooth Banach space $E$ which has a weakly sequentially continuous normalized duality mapping $j$ from $E$ to $E^{*}$ (cf. [9]). At that time, in [10], Sahu and Yao also extended the results of $\mathrm{Xu}[6]$ for the zero of an accretive operator in a Banach space which has a uniformly Gâteaux differentiable norm by combining the prox-Tikhonov method and the viscosity approximation method. They introduced the iterative method to define the sequence $\left\{x_{n}\right\}$ as follows:

$$
x_{n+1}=J_{r_{n}}^{A}\left(\left(1-\alpha_{n}\right) x_{n}+\alpha_{n} f\left(x_{n}\right)\right) \text {, }
$$

for all $n \in \mathbb{N}$, where $A$ is an accretive operator such that $S=A^{-1} 0 \neq \emptyset$ and $\overline{D(A)} \subset C \subset$ $\bigcap_{t>0} R(I+t A)$, and $f$ is a contractive mapping on $C$.

Zegeye and Shahzed [11] studied the convergence problem of finding a common zero of a finite family of $m$-accretive operators $(c f$. $[12,13])$. More precisely, they proved the following result.

Theorem 1.1 [11] Let E be a strictly convex and reflexive Banach space with a uniformly Gâteaux differentiable norm, $K$ be a nonempty, closed, and convex subset of $E$ and $A_{i}$ : $K \rightarrow E$ be an m-accretive operator, for each $i=1,2, \ldots, N$ with

$$
\bigcap_{i=1}^{N} A_{i}^{-1} 0 \neq \emptyset .
$$


For any $u, x_{0} \in K$, let $\left\{x_{n}\right\}$ be a sequence in $K$ generated by the algorithm:

$$
x_{n+1}=\alpha_{n} u+\left(1-\alpha_{n}\right) S_{N}\left(x_{n}\right), \quad \forall n \geq 0,
$$

where $S_{N}:=a_{0} I+a_{1} J^{A_{1}}+a_{2} J^{A_{2}}+\cdots+a_{N} J^{A_{N}}$ with $J^{A_{i}}=\left(I+A_{i}\right)^{-1}$ for $0<a_{i}<1, i=$ $0,1,2, \ldots, N, \sum_{i=0}^{N} a_{i}=1$, and $\left\{\alpha_{n}\right\}$ is a real sequence which satisfies the following conditions:

(i) $\lim _{n \rightarrow \infty} \alpha_{n}=0, \sum_{n=1}^{\infty} \alpha_{n}=\infty$,

(ii) $\sum_{n=1}^{\infty}\left|\alpha_{n}-\alpha_{n-1}\right|<\infty$ or $\lim _{n \rightarrow \infty} \frac{\left|\alpha_{n}-\alpha_{n-1}\right|}{\alpha_{n}}=0$.

If every nonempty, bounded, closed, and convex subset of $E$ has the fixed point property for nonexpansive mapping, then $\left\{x_{n}\right\}$ converges strongly to a common solution of the equations $A_{i}(x)=0$ for $i=1,2, \ldots, N$.

Motivated by Xu [6] and Zegeye and Shahzed [11], Tuyen [14] introduced an iterative algorithm as follows:

$$
\left\{\begin{array}{l}
x_{0} \in C, \\
x_{n+1}=S_{N}\left(\alpha_{n} f\left(x_{n}\right)+\left(1-\alpha_{n}\right) x_{n}\right), \quad \forall n \geq 0,
\end{array}\right.
$$

where $S_{N}:=a_{0} I+a_{1} J^{A_{1}}+a_{2} J^{A_{2}}+\cdots+a_{N} J^{A_{N}}$ with $a_{0}, a_{1}, \ldots, a_{N}$ in $(0,1)$ such that $\sum_{i=0}^{N} a_{i}=1$ and $\left\{\alpha_{n}\right\} \subset(0,1)$ is a real sequence of positive numbers. The result of Tuyen [14] is given by the following.

Theorem 1.2 [14] Let E be a strictly convex and reflexive Banach space which has a weakly continuous duality mapping $J_{\varphi}$ with gauge $\varphi$. Let $C$ be a nonempty, closed, and convex subset of $E$ and $f$ be a contraction mapping of $C$ into itself with the contractive coefficient $c \in(0,1)$. Let $A_{i}: C \rightarrow E$ be an m-accretive operator, for each $i=1,2, \ldots, N$ with

$$
\bigcap_{i=1}^{N} A_{i}^{-1} 0 \neq \emptyset
$$

Let $J^{A_{i}}=\left(I+A_{i}\right)^{-1}$ for $i=1,2, \ldots, N$. For any $x_{0} \in C$, let $\left\{x_{n}\right\}$ be a sequence generated by algorithm (1.10). If the sequence $\left\{\alpha_{n}\right\}$ satisfies the following conditions:

(i) $\lim _{n \rightarrow \infty} \alpha_{n}=0, \sum_{n=1}^{\infty} \alpha_{n}=\infty$,

(ii) $\sum_{n=1}^{\infty}\left|\alpha_{n}-\alpha_{n-1}\right|<\infty$ or $\lim _{n \rightarrow \infty} \frac{\left|\alpha_{n}-\alpha_{n-1}\right|}{\alpha_{n}}=0$,

then $\left\{x_{n}\right\}$ converges strongly to a common solution of the equations $A_{i}(x)=0$ for $i=$ $1,2, \ldots, N$.

In this paper, we combine the proximal point method [9] and the viscosity approximation method [15] with Meir-Keeler contractions to get strong convergence theorems for the problem of finding a common zero of a finite family of accretive operators in Banach spaces. We also give some applications of our results for the convex minimization problem and the variational inequality problem in Hilbert spaces.

\section{Preliminaries}

Let $E$ be a real Banach space and $M \subseteq E$. We denote by $F(T)$ the set of all fixed points of the mapping $T: M \rightarrow M$. 
Recall that a mapping $\phi:(X, d) \rightarrow(X, d)$ from the metric space $(X, d)$ into itself is said to be a Meir-Keeler contraction, if, for every $\varepsilon>0$, there exists $\delta>0$ such that $d(x, y)<\varepsilon+\delta$ implies

$$
d(\phi x, \phi y)<\varepsilon,
$$

for all $x, y \in X$. We know that if $(X, d)$ is a complete metric space, then $\phi$ has a unique fixed point [16]. In the sequel, we always use $\Sigma_{M}$ to denote the collection of all Meir-Keeler contractions on $M$ and $S_{E}$ to denote the unit sphere $S_{E}=\{x \in E:\|x\|=1\}$. A Banach space $E$ is said to be strictly convex if $x, y \in S_{E}$ with $x \neq y$, and, for all $t \in(0,1)$,

$$
\|(1-t) x+t y\|<1
$$

A Banach space $E$ is said to be smooth provided the limit

$$
\lim _{t \rightarrow 0} \frac{\|x+t y\|-\|x\|}{t}
$$

exists for each $x$ and $y$ in $S_{E}$. In this case, the norm of $E$ is said to be Gâteaux differentiable. It is said to be uniformly Gâteaux differentiable if for each $y \in S_{E}$, this limit is attained uniformly for $x \in S_{E}$. It is well known that every uniformly smooth Banach space has a uniformly Gâteaux differentiable norm.

A closed convex subset $C$ of a Banach space $E$ is said to have the fixed point property for nonexpansive mappings if every nonexpansive mapping of a nonempty, closed, and convex subset $M$ of $C$ into itself has a fixed point in $M$.

A subset $C$ of a Banach space $E$ is called a retract of $E$ if there is a continuous mapping $P$ from $E$ onto $C$ such that $P x=x$, for all $x \in C$. We call such $P$ a retraction of $E$ onto $C$. It follows that if $P$ is a retraction, then $P y=y$, for all $y$ in the range of $P$. A retraction $P$ is said to be sunny if $P(P x+t(x-P x))=P x$, for all $x \in E$ and $t \geq 0$. If a sunny retraction $P$ is also nonexpansive, then $C$ is said to be a sunny nonexpansive retract of $E$.

An accretive operator $A$ defined on a Banach space $E$ is said to satisfy the range condition if $\overline{D(A)} \subset R(I+\lambda A)$, for all $\lambda>0$, where $\overline{D(A)}$ denotes the closure of the domain of $A$. We know that for an accretive operator $A$ which satisfies the range condition, $A^{-1} 0=F\left(J_{\lambda}^{A}\right)$, for all $\lambda>0$.

Let $f$ be a continuous linear functional on $l_{\infty}$. We use $f_{n}\left(x_{n+m}\right)$ to denote

$$
f\left(x_{m+1}, x_{m+2}, \ldots, x_{m+n}, \ldots\right)
$$

for $m=0,1,2, \ldots$ A continuous linear functional $f$ on $l_{\infty}$ is called a Banach limit if $\|f\|=$ $f(e)=1$ and $f_{n}\left(x_{n}\right)=f_{n}\left(x_{n+1}\right)$ for each $x=\left(x_{1}, x_{2}, \ldots\right)$ in $l_{\infty}$. Fix any Banach limit and denote it by $L I M$. Note that $\|L I M\|=1$, and, for all $\left\{x_{n}\right\} \in l_{\infty}$,

$$
\liminf _{n \rightarrow \infty} x_{n} \leq L I M_{n} x_{n} \leq \limsup _{n \rightarrow \infty} x_{n}
$$

The following lemmas play crucial roles for the proof of main theorems in this paper. 
Lemma 2.1 [17] Let $\phi$ be a Meir-Keeler contraction on a convex subset $C$ of a Banach space E. Then for each $\varepsilon>0$, there exists $r \in(0,1)$ such that, for all $x, y \in C,\|x-y\| \geq \varepsilon$ implies

$$
\|\phi x-\phi y\| \leq r\|x-y\| .
$$

Remark 2.2 From Lemma 2.1, for each $\varepsilon>0$, there exists $r \in(0,1)$ such that

$$
\|\phi x-\phi y\| \leq \max \{\varepsilon, r\|x-y\|\}
$$

for all $x, y \in C$.

Lemma 2.3 [17] Let $C$ be a convex subset of a Banach space E. Let $T$ be a nonexpansive mapping on $C$ and $\phi$ be a Meir-Keeler contraction on $C$. Then, for each $t \in(0,1)$, a mapping $x \mapsto(1-t) T x+t \phi x$ is also a Meir-Keeler contraction on $C$.

Lemma 2.4 [18] Let C be a convex subset of a smooth Banach space E, D a nonempty subset of $C$, and $P$ a retraction from $C$ onto $D$. Then the following statements are equivalent:

(i) $P$ is sunny nonexpansive.

(ii) $\langle x-P x, j(z-P x)\rangle \leq 0$, for all $x \in C, z \in D$.

(iii) $\langle x-y, j(P x-P y)\rangle \geq\|P x-P y\|^{2}$, for all $x, y \in C$.

We can easily prove the following lemma from Lemma 1 in [19].

Lemma 2.5 [19] Let E be a Banach space with a uniformly Gâteaux differentiable norm, $C$ a nonempty, closed, and convex subset of $E$ and $\left\{x_{n}\right\}$ a bounded sequence in E. Let LIM be a Banach limit and $y \in C$ such that

$$
\operatorname{LIM}_{n}\left\|x_{n}-y\right\|^{2}=\inf _{x \in C} L I M_{n}\left\|x_{n}-x\right\|^{2} .
$$

Then $\operatorname{LIM}_{n}\left\langle x-y, j\left(x_{n}-y\right)\right\rangle \leq 0$, for all $x \in C$.

Lemma 2.6 [20] Let $\left\{a_{n}\right\},\left\{b_{n}\right\},\left\{\sigma_{n}\right\}$ be sequences of positive numbers satisfying the inequality:

$$
a_{n+1} \leq\left(1-b_{n}\right) a_{n}+\sigma_{n}, \quad b_{n}<1 .
$$

If $\sum_{n=0}^{\infty} b_{n}=+\infty$ and $\lim _{n \rightarrow \infty} \sigma_{n} / b_{n}=0$, then $\lim _{n \rightarrow \infty} a_{n}=0$.

Lemma 2.7 [21] Let E be a Banach space with a uniformly Gâteaux differentiable norm and let $C$ be a nonempty, closed, and convex subset of $E$ with fixed point property for nonexpansive self-mappings. Let $A: D(A) \subset E \rightarrow 2^{E}$ be an accretive operator such that $A^{-1} 0 \neq \emptyset$ and $\overline{D(A)} \subset \bigcap_{t>0} R(I+t A)$. Then $A^{-1} 0$ is a sunny nonexpansive retract of $C$.

Lemma 2.8 [11] Let $C$ be a nonempty, closed, and convex subset of a strictly convex Banach space $E$. Let $A_{i}: C \rightarrow E$ be an m-accretive operator for each $i=1,2, \ldots, N$ with $\bigcap_{i=1}^{N} N\left(A_{i}\right) \neq \emptyset$. Let $a_{0}, a_{1}, \ldots, a_{N}$ be real numbers in $(0,1)$ such that $\sum_{i=0}^{N} a_{i}=1$ and let $S_{N}:=a_{0} I+a_{1} J^{A_{1}}+a_{2} J^{A_{2}}+\cdots+a_{N} J^{A_{N}}$, where $J^{A_{i}}:=\left(I+A_{i}\right)^{-1}$. Then $S_{N}$ is a nonexpansive mapping and $F\left(S_{N}\right)=\bigcap_{i=1}^{N} N\left(A_{i}\right)$. 


\section{Main results}

Now, we are in a position to introduce and prove the main theorems.

Propositon 3.1 Let E be a reflexive Banach space with a uniformly Gâteaux differentiable norm and let $C$ be a closed convex subset of $E$ which has the fixed point property for nonexpansive mappings. Let $T$ be a nonexpansive mapping on $C$. Then for each $\phi \in \Sigma_{C}$ and every $t \in(0,1)$, there exists a unique fixed point $v_{t} \in C$ of the Meir-Keeler contraction $C \ni v_{t} \mapsto t \phi v_{t}+(1-t) T v_{t}$, such that $\left\{v_{t}\right\}$ converges strongly to $x^{*} \in F(T)$ as $t \rightarrow 0$ which solves the variational inequality:

$$
\left\langle x^{*}-\phi x^{*}, j\left(x^{*}-x\right)\right\rangle \leq 0,
$$

for all $x \in F(T)$.

Proof By Lemma 2.3, the mapping $C \ni v \mapsto t \phi v+(1-t) T v$ is a Meir-Keeler contraction on $C$. So, there is a unique $v_{t} \in C$ which satisfies

$$
v_{t}=t \phi v_{t}+(1-t) T v_{t}
$$

Now we show that $\left\{v_{t}\right\}$ is bounded. Indeed, take a $p \in F(T)$ and a number $\varepsilon>0$.

Case 1 . Let $\left\|v_{t}-p\right\| \leq \varepsilon$. Then we can see easily that $\left\{v_{t}\right\}$ is bounded.

Case 2. Let $\left\|v_{t}-p\right\| \geq \varepsilon$. Then, by Lemma 2.4, there exists $r \in(0,1)$ such that

$$
\left\|\phi v_{t}-\phi p\right\| \leq r\left\|v_{t}-p\right\| .
$$

So, we have

$$
\begin{aligned}
\left\|v_{t}-p\right\| & =\left\|t \phi v_{t}+(1-t) T v_{t}-p\right\| \\
& \leq t\left\|\phi v_{t}-\phi p\right\|+t\|\phi p-p\|+(1-t)\left\|v_{t}-p\right\| \\
& \leq r t\left\|v_{t}-p\right\|+t\|\phi p-p\|+(1-t)\left\|v_{t}-p\right\| .
\end{aligned}
$$

Therefore,

$$
\left\|v_{t}-p\right\| \leq \frac{\|\phi p-p\|}{1-r} .
$$

Hence, we conclude that $\left\{v_{t}\right\}$ is bounded and $\left\{\phi v_{t}\right\},\left\{T v_{t}\right\}$ are also bounded.

By the boundedness of $\left\{v_{t}\right\},\left\{\phi v_{t}\right\}$, and $\left\{T v_{t}\right\}$, we have

$$
\left\|v_{t}-T v_{t}\right\|=t\left\|\phi v_{t}-T v_{t}\right\| \rightarrow 0 \quad \text { as } t \rightarrow 0
$$

Assume $t_{n} \rightarrow 0$. Set $v_{n}:=v_{t_{n}}$ and define $\varphi: C \rightarrow \mathbb{R}^{+}$by

$$
\varphi(x)=L I M_{n}\left\|v_{n}-x\right\|^{2},
$$

for all $x \in C$ and let

$$
M=\left\{y \in C: \varphi(y)=\inf _{x \in C} \varphi(x)\right\} .
$$


Since $E$ is reflexive, $\varphi(x) \rightarrow \infty$ as $\|x\| \rightarrow \infty$, and $\varphi$ is a continuous convex function, from Barbu and Precupanu [22], we know that $M$ is a nonempty subset of $C$. By Takahashi [23], we see that $M$ is also closed, convex, and bounded.

For all $x \in M$, from $\left\|v_{n}-T v_{n}\right\| \rightarrow 0$ as $n \rightarrow \infty$, we have

$$
\begin{aligned}
\varphi(T x) & =\operatorname{LIM}_{n}\left\|v_{n}-T x\right\|^{2} \\
& \leq \operatorname{LIM}_{n}\left(\left\|v_{n}-T v_{n}\right\|+\left\|T v_{n}-T x\right\|\right)^{2} \\
& \leq \operatorname{LIM}_{n}\left\|T v_{n}-T x\right\|^{2} \\
& \leq \operatorname{LIM}_{n}\left\|v_{n}-x\right\|^{2} \\
& =\varphi(x) .
\end{aligned}
$$

So, $M$ is invariant under $T$, i.e., $T(M) \subset M$. By assumption, we have $M \cap F(T) \neq \emptyset$. Let $x^{*} \in M \cap F(T)$. By Lemma 2.7, we obtain

$$
\operatorname{LIM}_{n}\left\langle x-x^{*}, j\left(v_{n}-x^{*}\right)\right\rangle \leq 0,
$$

for all $x \in C$. In particular,

$$
\operatorname{LIM}_{n}\left\langle\phi x^{*}-x^{*}, j\left(v_{n}-x^{*}\right)\right\rangle \leq 0 .
$$

Suppose that $L I M_{n}\left\|v_{n}-x^{*}\right\|^{2} \geq \varepsilon>0$. By (2.1),

$$
\limsup _{n \rightarrow \infty}\left\|v_{n}-x^{*}\right\|^{2} \geq \varepsilon
$$

So, there exists a subsequence $\left\{v_{n_{k}}\right\}$ of $\left\{v_{n}\right\}$ such that, for all $k \geq 1$,

$$
\left\|v_{n_{k}}-x^{*}\right\| \geq \varepsilon_{0},
$$

where $\varepsilon_{0} \in(0, \sqrt{\varepsilon})$. By Lemma 2.3, there is $r_{0} \in(0,1)$ such that

$$
\left\|\phi v_{n_{k}}-\phi x^{*}\right\| \leq r\left\|v_{n_{k}}-x^{*}\right\| .
$$

From

$$
\left\langle T v_{n_{k}}-v_{n_{k}}, j\left(v_{n_{k}}-x^{*}\right)\right\rangle \leq 0,
$$

for all $k \geq 1$, we have

$$
\begin{aligned}
\left\|v_{n_{k}}-x^{*}\right\|^{2} & =t\left\langle\phi v_{n_{k}}-x^{*}, j\left(v_{n_{k}}-x^{*}\right)\right\rangle+(1-t)\left\langle T v_{n_{k}}-x^{*}, j\left(v_{n_{k}}-x^{*}\right)\right\rangle \\
& \leq t\left\langle\phi v_{n_{k}}-x^{*}, j\left(v_{n_{k}}-x^{*}\right)\right\rangle+(1-t)\left\|v_{n_{k}}-x^{*}\right\|^{2},
\end{aligned}
$$

which implies that

$$
\begin{aligned}
\left\|v_{n_{k}}-x^{*}\right\|^{2} & \leq\left\langle\phi v_{n_{k}}-x^{*}, j\left(v_{n_{k}}-x^{*}\right)\right\rangle \\
& \leq\left\langle\phi v_{n_{k}}-x, j\left(v_{n_{k}}-x^{*}\right)\right\rangle+\left\langle\phi x-x^{*}, j\left(v_{n_{k}}-x^{*}\right)\right\rangle,
\end{aligned}
$$


for all $x \in C$. So, from (3.2), we get

$$
\begin{aligned}
\operatorname{LIM}_{n}\left\|v_{n_{k}}-x^{*}\right\|^{2} & \leq L I M_{n}\left\langle\phi v_{n_{k}}-x, j\left(v_{n_{k}}-x^{*}\right)\right\rangle+\operatorname{LIM}_{n}\left\langle\phi x-x^{*}, j\left(v_{n_{k}}-x^{*}\right)\right\rangle \\
& \leq L I M_{n}\left\|\phi v_{n_{k}}-x\right\|\left\|v_{n_{k}}-x^{*}\right\|
\end{aligned}
$$

for all $x \in C$. In particular,

$$
\begin{aligned}
\operatorname{LIM}_{n}\left\|v_{n_{k}}-x^{*}\right\|^{2} & \leq \operatorname{LIM}_{n}\left\|\phi v_{n_{k}}-\phi x^{*}\right\|\left\|v_{n_{k}}-x^{*}\right\| \\
& \leq r_{0} L I M_{n}\left\|v_{n_{k}}-x^{*}\right\|^{2}
\end{aligned}
$$

which is a contradiction. Hence, $\operatorname{LIM}_{n}\left\|v_{n}-x^{*}\right\|=0$ and there exists a subsequence $\left\{v_{n_{k}}\right\}$ of $\left\{v_{n}\right\}$ such that $v_{n_{k}} \rightarrow x^{*}$ as $k \rightarrow \infty$.

Assume that $\left\{v_{n_{l}}\right\}$ is another subsequence of $\left\{v_{n}\right\}$ such that $v_{n_{l}} \rightarrow y^{*}$ with $y^{*} \neq x^{*}$. It is easy to see that $y^{*} \in F(T)$. By Lemma 2.3 , there exists $r_{1} \in(0,1)$ such that

$$
\left\|\phi x^{*}-\phi y^{*}\right\| \leq r_{1}\left\|x^{*}-y^{*}\right\|
$$

Observe that

$$
\begin{aligned}
\mid\left\langle v_{n}-\right. & \left.\phi v_{n}, j\left(v_{n}-y^{*}\right)\right\rangle-\left\langle x^{*}-\phi x^{*}, j\left(x^{*}-y^{*}\right)\right\rangle \mid \\
\leq & \left|\left\langle v_{n}-\phi v_{n}, j\left(v_{n}-y^{*}\right)\right\rangle-\left\langle x^{*}-\phi x^{*}, j\left(v_{n}-y^{*}\right)\right\rangle\right| \\
& +\left|\left\langle x^{*}-\phi x^{*}, j\left(v_{n}-y^{*}\right)\right\rangle-\left\langle x^{*}-\phi x^{*}, j\left(x^{*}-y^{*}\right)\right\rangle\right| \\
\leq & \left\|v_{n}-\phi v_{n}-\left(x^{*}-\phi x^{*}\right)\right\|\left\|v_{n}-y^{*}\right\|+\left|\left\langle x^{*}-\phi x^{*}, j\left(v_{n}-y^{*}\right)-j\left(x^{*}-y^{*}\right)\right\rangle\right|,
\end{aligned}
$$

for all $n \in \mathbb{N}$. Since $v_{n_{k}} \rightarrow x^{*}$ and $j$ is norm to weak* uniformly continuous, we obtain

$$
\left\langle x^{*}-\phi x^{*}, j\left(x^{*}-y^{*}\right)\right\rangle \leq 0 .
$$

Similarly, we have

$$
\left\langle y^{*}-\phi y^{*}, j\left(y^{*}-x^{*}\right)\right\rangle \leq 0 .
$$

Adding the above two inequalities yields

$$
\left\langle x^{*}-y^{*}-\left(\phi x^{*}-\phi y^{*}\right), j\left(x^{*}-y^{*}\right)\right\rangle \leq 0,
$$

and combining with (3.4) implies that

$$
\left\|x^{*}-y^{*}\right\| \leq r_{1}\left\|x^{*}-y^{*}\right\|,
$$

which is a contradiction. Hence $\left\{v_{t_{n}}\right\}$ converges strongly to $x^{*}$.

Now, we prove that the net $\left\{v_{t}\right\}$ converges strongly to $x^{*}$ as $t \rightarrow 0$. We assume that there is another subsequence $\left\{s_{n}\right\}$ with $s_{n} \in(0,1)$, for all $n$ and $s_{n} \rightarrow 0$ as $n \rightarrow \infty$ such that $v_{s_{n}} \rightarrow z^{*}$ as $n \rightarrow \infty$. Then we have $z^{*} \in F(T)$. For each $t$ and $z \in F(T)$, we have

$$
\left\langle v_{t}-\phi v_{t}, j\left(v_{t}-z\right)\right\rangle=\frac{1-t}{t}\left\langle T v_{t}-v_{t}, j\left(v_{t}-z\right)\right\rangle \leq 0 .
$$


So, we obtain

$$
\left\langle v_{t_{n}}-\phi v_{t_{n}}, j\left(v_{t_{n}}-z^{*}\right)\right\rangle \leq 0
$$

and similarly, we have

$$
\left\langle v_{s_{n}}-\phi v_{s_{n}}, j\left(v_{s_{n}}-x^{*}\right)\right\rangle \leq 0,
$$

which implies that

$$
\left\langle x^{*}-\phi x^{*}, j\left(x^{*}-z^{*}\right)\right\rangle \leq 0
$$

and

$$
\left\langle z^{*}-\phi z^{*}, j\left(z^{*}-x^{*}\right)\right\rangle \leq 0
$$

Thus, we have $x^{*}=z^{*}$. Therefore, $\left\{v_{t}\right\}$ converges strongly to $x^{*}$ and it is easy to see that $x^{*}$ solves the variational inequality

$$
\left\langle x^{*}-\phi x^{*}, j\left(x^{*}-x\right)\right\rangle \leq 0,
$$

for all $x \in F(T)$. This completes the proof.

Remark 3.2 Let $Q$ be a sunny nonexpansive retraction from $C$ onto $F(T)$. By the uniqueness of $Q$, inequality (3.1) and Lemma 2.4, we obtain $Q \phi x^{*}=x^{*}$.

Proposition 3.3 Let $C$ be a closed convex subset of a reflexive Banach space $E$ with a uniformly Gâteaux differentiable norm and let $T$ be a nonexpansive mapping on $C$ with $F(T) \neq \emptyset$. Assume $\left\{x_{n}\right\}$ is a bounded sequence such that $x_{n}-T x_{n} \rightarrow 0$ as $n \rightarrow \infty$. Let $x_{t}=t \phi x_{t}+(1-t) T x_{t}$, for all $t \in(0,1)$, where $\phi \in \Sigma_{C}$. Assume that $x^{*}=\lim _{t \rightarrow 0} x_{t}$ exists. Then we have

$$
\limsup _{n \rightarrow \infty}\left\langle(\phi-I) x^{*}, j\left(x_{n}-x^{*}\right)\right\rangle \leq 0 \text {. }
$$

Proof Set $M=\sup \left\{\left\|x_{n}-x_{t}\right\|: t \in(0,1), n \geq 0\right\}$. Then we have

$$
\begin{aligned}
\left\|x_{t}-x_{n}\right\|^{2}= & t\left\langle\phi x_{t}-x_{n}, j\left(x_{t}-x_{n}\right)\right\rangle+(1-t)\left\langle T x_{t}-x_{n}, j\left(x_{t}-x_{n}\right)\right\rangle \\
= & t\left\langle\phi x_{t}-x_{t}, j\left(x_{t}-x_{n}\right)\right\rangle+(1-t)\left\langle T x_{t}-T x_{n}, j\left(x_{t}-x_{n}\right)\right\rangle \\
& +(1-t)\left\langle T x_{n}-x_{n}, j\left(x_{t}-x_{n}\right)\right\rangle \\
\leq & t\left\langle\phi x_{t}-x_{t}, j\left(x_{t}-x_{n}\right)\right\rangle+t\left\|x_{t}-x_{n}\right\|^{2} \\
& +(1-t)\left\|x_{t}-x_{n}\right\|^{2}+M\left\|x_{n}-T x_{n}\right\|,
\end{aligned}
$$

which implies that

$$
\left\langle\phi x_{t}-x_{t}, j\left(x_{n}-x_{t}\right)\right\rangle \leq \frac{M}{t}\left\|x_{n}-T x_{n}\right\| .
$$


Fix $t$ and letting $n \rightarrow \infty$ yields

$$
\limsup _{n \rightarrow \infty}\left\{(\phi-I) x^{*}, j\left(x_{n}-x^{*}\right)\right\rangle \leq 0 .
$$

This completes the proof.

Now, let $E$ be a reflexive and strictly convex Banach space with a uniformly Gâteaux differentiable norm and $C$ a closed convex subset of $E$ which has the fixed point property for nonexpansive mappings. Let $A_{i}: E \rightarrow 2^{E}$ be an accretive operator, for each $i=1,2, \ldots, N$ such that

$$
S=\bigcap_{i=1}^{N} A_{i}^{-1} 0 \neq \emptyset
$$

and

$$
\overline{D\left(A_{i}\right)} \subset C \subset \bigcap_{r>0} R\left(I+r A_{i}\right),
$$

for all $i=1,2, \ldots, N$.

For each $\phi \in \Sigma_{C}$, we study the strong convergence of the sequence $\left\{z_{n}\right\}$ defined by

$$
\left\{\begin{array}{l}
z_{0} \in C, \\
z_{n+1}=S_{N}\left(\alpha_{n} \phi z_{n}+\left(1-\alpha_{n}\right) z_{n}\right), \quad \forall n \geq 0,
\end{array}\right.
$$

where $S_{N}:=a_{0} I+a_{1} J^{A_{1}}+a_{2} J^{A_{2}}+\cdots+a_{N} J^{A_{N}}$ with $a_{0}, a_{1}, \ldots, a_{N}$ are real numbers in $(0,1)$ such that $\sum_{i=0}^{N} a_{i}=1$ and $\left\{\alpha_{n}\right\} \subset(0,1)$ is a real sequence of positive numbers, under the conditions:

(C1) $\lim _{n \rightarrow \infty} \alpha_{n}=0, \sum_{n=1}^{\infty} \alpha_{n}=\infty$,

(C2) $\sum_{n=1}^{\infty}\left|\alpha_{n}-\alpha_{n-1}\right|<\infty$ or $\lim _{n \rightarrow \infty} \frac{\left|\alpha_{n}-\alpha_{n-1}\right|}{\alpha_{n}}=0$.

Then we have the following theorem.

Theorem 3.4 If the sequence $\left\{\alpha_{n}\right\}$ satisfies the conditions (C1)-(C2), then the sequence $\left\{x_{n}\right\}$ generated by

$$
x_{n+1}=S_{N}\left(\alpha_{n} u+\left(1-\alpha_{n}\right) x_{n}\right), \quad \forall n \geq 0,
$$

converges strongly to $Q u$, where $u \in C$ and $Q$ is a sunny nonexpansive retraction from $C$ onto $S$.

Proof By Lemma 2.8, we have $F\left(S_{N}\right)=\bigcap_{i=1}^{N} A_{i}^{-1} 0 \neq \emptyset$. Now, for each $p \in F\left(S_{N}\right)$, we have

$$
\begin{aligned}
\left\|x_{n+1}-p\right\| & =\left\|S_{N}\left(\alpha_{n} u+\left(1-\alpha_{n}\right) x_{n}\right)-S_{N}(p)\right\| \\
& \leq\left(1-\alpha_{n}\right)\left\|x_{n}-p\right\|+\alpha_{n}\|u-p\| \\
& \leq \max \left\{\left\|x_{n}-p\right\|,\|u-p\|\right\} \\
& \vdots \\
& \leq \max \left\{\left\|x_{0}-p\right\|,\|u-p\|\right\} .
\end{aligned}
$$


Hence $\left\{x_{n}\right\}$ is bounded. Suppose that $\max \left\{\sup \left\|x_{n}\right\|,\|u\|\right\} \leq K$. It follows that

$$
\begin{aligned}
\left\|x_{n+1}-S_{N}\left(x_{n}\right)\right\| & =\left\|S_{N}\left(\alpha_{n} f\left(x_{n}\right)+\left(1-\alpha_{n}\right) x_{n}\right)-S_{N}\left(x_{n}\right)\right\| \\
& \leq \alpha_{n}\left\|f\left(x_{n}\right)-x_{n}\right\| \rightarrow 0, \quad \text { as } n \rightarrow \infty
\end{aligned}
$$

From (1.10), we get

$$
\begin{aligned}
\left\|x_{n+1}-x_{n}\right\| & =\left\|S_{N}\left(\alpha_{n} u+\left(1-\alpha_{n}\right) x_{n}\right)-S_{N}\left(\alpha_{n-1} u+\left(1-\alpha_{n-1}\right) x_{n-1}\right)\right\| \\
& \leq\left(1-\alpha_{n}\right)\left\|x_{n}-x_{n-1}\right\|+\alpha_{n} \beta_{n},
\end{aligned}
$$

where $\beta_{n}=2 K \frac{\left|\alpha_{n}-\alpha_{n-1}\right|}{\alpha_{n}}$.

We consider two cases of condition (C2).

First, suppose that $\sum_{n=1}^{\infty}\left|\alpha_{n}-\alpha_{n-1}\right|<\infty$. Then

$$
\left\|x_{n+1}-x_{n}\right\| \leq\left(1-\alpha_{n}\right)\left\|x_{n}-x_{n-1}\right\|+\sigma_{n}
$$

where $\sigma_{n}=2 K\left|\alpha_{n}-\alpha_{n-1}\right|$. So, we have $\sum_{n=1}^{\infty} \sigma_{n}<\infty$.

Second, suppose that $\lim _{n \rightarrow \infty} \frac{\left|\alpha_{n}-\alpha_{n-1}\right|}{\alpha_{n}}=0$. Then

$$
\left\|x_{n+1}-x_{n}\right\| \leq\left(1-\alpha_{n}\right)\left\|x_{n}-x_{n-1}\right\|+\sigma_{n}
$$

where $\sigma_{n}=\alpha_{n} \beta_{n}$. So, we have $\sigma_{n}=o\left(\alpha_{n}\right)$.

For any case, we have $\left\|x_{n+1}-x_{n}\right\| \rightarrow 0$ as $n \rightarrow \infty$, from Lemma 2.6. By (3.9) we obtain

$$
\left\|x_{n}-S_{N} x_{n}\right\| \leq\left\|x_{n+1}-x_{n}\right\|+\left\|x_{n+1}-S_{N} x_{n}\right\| \rightarrow 0 \quad \text { as } n \rightarrow \infty
$$

Let $y_{n}=\alpha_{n} u+\left(1-\alpha_{n}\right) x_{n}$. Then we have

$$
\left\|y_{n}-x_{n}\right\|=\alpha_{n}\left\|u-x_{n}\right\| \rightarrow 0 \quad \text { as } n \rightarrow \infty
$$

it follows that

$$
\begin{aligned}
\left\|y_{n}-S_{N} y_{n}\right\| & \leq\left\|y_{n}-x_{n}\right\|+\left\|x_{n}-S_{N} x_{n}\right\|+\left\|S_{N} x_{n}-S_{N} y_{n}\right\| \\
& \leq 2\left\|y_{n}-x_{n}\right\|+\left\|x_{n}-S_{N} x_{n}\right\| \rightarrow 0 \quad \text { as } n \rightarrow \infty
\end{aligned}
$$

For each $t \in(0,1)$, let $x_{t}=t u+(1-t) S_{N} x_{t}$. Apply Proposition 3.1 with $\phi x=u$, for all $x \in C$, we know that $\left\{x_{t}\right\}$ converges strongly to $x^{*} \in F\left(S_{N}\right)$, satisfying $Q u=x^{*}$. It follows from Proposition 3.3 that

$$
\limsup _{n \rightarrow \infty}\left\langle u-x^{*}, j\left(y_{n}-x^{*}\right)\right\rangle \leq 0 .
$$

Observe that

$$
\begin{aligned}
\left\|y_{n}-x^{*}\right\|^{2} & =\left\langle\alpha_{n} u+\left(1-\alpha_{n}\right) x_{n}-x^{*}, j\left(y_{n}-x^{*}\right)\right\rangle \\
& \leq\left(1-\alpha_{n}\right)\left\|x_{n}-x^{*}\right\|\left\|y_{n}-x^{*}\right\|+\alpha_{n}\left\langle u-x^{*}, j\left(y_{n}-x^{*}\right)\right\rangle \\
& \leq \frac{\left(1-\alpha_{n}\right)}{2}\left(\left\|x_{n}-x^{*}\right\|^{2}+\left\|y_{n}-x^{*}\right\|^{2}\right)+\alpha_{n}\left\langle u-x^{*}, j\left(y_{n}-x^{*}\right)\right\rangle .
\end{aligned}
$$


Hence, we have

$$
\left\|y_{n}-x^{*}\right\|^{2} \leq\left(1-\alpha_{n}\right)\left\|x_{n}-x^{*}\right\|^{2}+2 \alpha_{n}\left\langle u-x^{*}, j\left(y_{n}-x^{*}\right)\right\rangle .
$$

Next, we have

$$
\left\|x_{n+1}-x^{*}\right\|^{2} \leq\left(1-\alpha_{n}\right)\left\|x_{n}-x^{*}\right\|^{2}+2 \alpha_{n}\left\langle u-x^{*}, j\left(y_{n}-x^{*}\right)\right\rangle .
$$

From Lemma 2.6, we have the desired result. That is, the sequence $\left\{x_{n}\right\}$ converges strongly to $Q u=x^{*}$. This completes the proof.

The following is a strong convergence theorem for the sequence $\left\{z_{n}\right\}$ in (3.6).

Theorem 3.5 If the sequence $\left\{\alpha_{n}\right\}$ satisfies the conditions (C1)-(C2), then the sequence $\left\{z_{n}\right\}$ generated by (3.6) converges strongly to $x^{*} \in S$, which satisfies $Q \phi x^{*}=x^{*}$, where $Q$ is a sunny nonexpansive retraction from $C$ onto $S$.

Proof Let $x^{*}$ be a unique fixed point of $Q \phi$, that is, $Q \phi x^{*}=x^{*}$. Let $\left\{x_{n}\right\}$ be a sequence defined by

$$
x_{n+1}=S_{N}\left(\alpha_{n} \phi x^{*}+\left(1-\alpha_{n}\right) x_{n}\right), \quad \text { for all } n \geq 0 .
$$

By Theorem 3.4, $x_{n} \rightarrow Q \phi x^{*}=x^{*}$ as $n \rightarrow \infty$.

Now, we prove that $\left\|z_{n}-x_{n}\right\| \rightarrow 0$ as $n \rightarrow \infty$. Assume that

$$
\limsup _{n \rightarrow \infty}\left\|z_{n}-x_{n}\right\|>0
$$

Then we choose $\varepsilon$ with $\varepsilon \in\left(0, \lim \sup _{n \rightarrow \infty}\left\|z_{n}-x_{n}\right\|\right)$. By Lemma 2.3, there exists $r \in(0,1)$ satisfying (2.2). We also choose $n_{1} \in \mathbb{N}$ such that

$$
\frac{r\left\|x_{n}-x^{*}\right\|}{1-r}<\varepsilon
$$

for all $n \geq n_{1}$. We divide this into the following two cases:

(i) There exists $n_{2} \in \mathbb{N}$ satisfying $n_{2} \geq n_{1}$ and $\left\|z_{n_{2}}-x_{n_{2}}\right\| \leq \varepsilon$.

(ii) $\left\|z_{n}-x_{n}\right\|>\varepsilon$, for all $n \geq n_{1}$.

In the case of (i), we have

$$
\begin{aligned}
\left\|z_{n_{2}+1}-x_{n_{2}+1}\right\| \leq & \left(1-\alpha_{n_{2}}\right)\left\|z_{n_{2}}-x_{n_{2}}\right\|+\alpha_{n_{2}}\left\|\phi z_{n_{2}}-\phi x^{*}\right\| \\
\leq & \left(1-\alpha_{n_{2}}\right)\left\|z_{n_{2}}-x_{n_{2}}\right\|+\alpha_{n_{2}} \max \left\{r\left\|z_{n_{2}}-x^{*}\right\|, \varepsilon\right\} \\
\leq & \max \left\{\left(1-\alpha_{n_{2}}+r \alpha_{n_{2}}\right)\left\|z_{n_{2}}-x_{n_{2}}\right\|+\alpha_{n_{2}}(1-r) \frac{r\left\|x_{n}-x^{*}\right\|}{1-r},\right. \\
& \left.\left(1-\alpha_{n_{2}}\right)\left\|z_{n_{2}}-x_{n_{2}}\right\|+\alpha_{n_{2}} \varepsilon\right\} \\
\leq & \varepsilon .
\end{aligned}
$$


By induction, we can show that $\left\|z_{n}-x_{n}\right\| \leq \varepsilon$, for all $n \geq n_{2}$. This is a contradiction to the fact that $\varepsilon<\lim \sup _{n \rightarrow \infty}\left\|z_{n}-x_{n}\right\|$.

In the case of (ii), for each $n \geq n_{1}$, we have

$$
\begin{aligned}
\left\|z_{n+1}-x_{n+1}\right\| & \leq\left(1-\alpha_{n}\right)\left\|z_{n}-x_{n}\right\|+\alpha_{n}\left\|\phi z_{n}-\phi x^{*}\right\| \\
& \leq\left(1-\alpha_{n}\right)\left\|z_{n}-x_{n}\right\|+\alpha_{n}\left\|\phi z_{n}-\phi x_{n}\right\|+\alpha_{n}\left\|\phi x_{n}-\phi x^{*}\right\| \\
& \leq\left[1-\alpha_{n}(1-r)\right]\left\|z_{n}-x_{n}\right\|+\alpha_{n}\left\|\phi x_{n}-\phi x^{*}\right\| .
\end{aligned}
$$

So, by Lemma 2.1, we get $\lim _{n \rightarrow \infty}\left\|z_{n}-x_{n}\right\|=0$. This is a contradiction. Therefore $\lim _{n \rightarrow \infty}\left\|z_{n}-x_{n}\right\|=0$. Thus we obtain

$$
\lim _{n \rightarrow \infty}\left\|z_{n}-x^{*}\right\| \leq \lim _{n \rightarrow \infty}\left\|z_{n}-x_{n}\right\|+\lim _{n \rightarrow \infty}\left\|x_{n}-x^{*}\right\|=0 .
$$

Hence $\left\{z_{n}\right\}$ convergence strongly to $Q \phi x^{*}=x^{*}$. This completes the proof.

Corollary 3.6 Let E be a reflexive and strictly convex Banach space with a uniformly Gâteaux differentiable norm and let $C$ be a closed convex subset of $E$ which has the fixed point property for nonexpansive mappings. Let $A_{i}: E \rightarrow 2^{E}$ be an m-accretive operator, for each $i=1,2, \ldots, N$ such that

$$
S=\bigcap_{i=1}^{N} A_{i}^{-1} 0 \neq \emptyset .
$$

For each $\phi \in \Sigma_{C}$, let $\left\{z_{n}\right\}$ be a sequence generated by (3.6). If the sequence $\left\{\alpha_{n}\right\}$ satisfies the conditions $(\mathrm{C} 1)-(\mathrm{C} 2)$, then the sequence $\left\{z_{n}\right\}$ converges strongly to $x^{*} \in S$ which satisfies $Q \phi x^{*}=x^{*}$, where $Q$ is a sunny nonexpansive retraction from $C$ onto $S$.

Proof Since for each $i=1,2, \ldots, N, A_{i}$ is an $m$-accretive operator, the condition $\overline{D\left(A_{i}\right)} \subset$ $C \subset \bigcap_{r>0} R\left(I+r A_{i}\right)$ is satisfied, for all $i=1,2, \ldots, N$. By the assumption and Theorem 3.5, we have $z_{n} \rightarrow x^{*}$ as $n \rightarrow \infty$ which satisfies $Q \phi x^{*}=x^{*}$. This completes the proof.

Remark 3.7 Corollary 3.6 is a generalization of the results of Tuyen [14], Zegeye and Shahzad [11] and Jung [24].

Remark 3.8 If we take $r=1$, then we may take $S_{1}:=J^{A}=(I+A)^{-1}$ and strict convexity of $E$ and the real constants $a_{i}, i=0,1$, may not be needed.

Corollary 3.9 Let E be a reflexive and strictly convex Banach space with a uniformly Gâteaux differentiable norm and let $C$ be a closed convex subset of $E$ which has the fixed point property for nonexpansive mappings. Let $A: E \rightarrow 2^{E}$ be an m-accretive operator such that $S=A^{-1} 0 \neq \emptyset$. For each $\phi \in \Sigma_{C}$, let $\left\{z_{n}\right\}$ be a sequence defined by

$$
\left\{\begin{array}{l}
z_{0} \in C \\
z_{n+1}=J^{A}\left(\alpha_{n} \phi z_{n}+\left(1-\alpha_{n}\right) z_{n}\right),
\end{array}\right.
$$

for all $n \geq 0$. If the sequence $\left\{\alpha_{n}\right\}$ satisfies the conditions (C1)-(C2), then the sequence $\left\{z_{n}\right\}$ converges strongly to $x^{*} \in S$ which satisfies $Q \phi x^{*}=x^{*}$, where $Q$ is a sunny nonexpansive retraction from $C$ onto $S$. 
Remark 3.10 Corollary 3.9 is a generalization of the results of Tuyen in [8].

\section{Applications}

In this section, we give some applications in the framework of Hilbert spaces. We first apply Corollary 3.9 to the convex minimization problem.

Theorem 4.1 Let $H$ be a Hilbert space and let $f: H \rightarrow(-\infty, \infty]$ be a proper lower semicontinuous convex function such that $(\partial f)^{-1} 0 \neq \emptyset$ for a subdifferential mapping $\partial f$ off . Let $\left\{x_{n}\right\}$ be a sequence defined as follows:

$$
\left\{\begin{array}{l}
x_{0} \in H \\
y_{n}=\alpha_{n} \phi x_{n}+\left(1-\alpha_{n}\right) x_{n} \\
x_{n+1}=\operatorname{argmin}_{z \in H}\left\{f(z)+\frac{1}{2}\left\|z-y_{n}\right\|^{2}\right\}
\end{array}\right.
$$

for all $n \geq 0$, where $\left\{\alpha_{n}\right\}$ is a sequence positive real numbers and $\phi \in \Sigma_{H}$. If the sequence $\left\{\alpha_{n}\right\}$ satisfies the conditions (C1)-(C2), then the sequence $\left\{x_{n}\right\}$ converges strongly to $x^{*}$ in $(\partial f)^{-1} 0$.

Proof By the Rockafellar theorem [25] (cf. [26]), the subdifferential mapping $\partial f$ is maximal monotone in $H$. So,

$$
x_{n+1}=\underset{z \in H}{\operatorname{argmin}}\left\{f(z)+\frac{1}{2}\left\|z-y_{n}\right\|^{2}\right\}
$$

is equivalent to $\partial f\left(x_{n+1}\right)+x_{n+1} \ni y_{n}$. Using Corollary $3.9,\left\{x_{n}\right\}$ converges strongly to an element $x^{*}$ in $(\partial f)^{-1} 0$. This completes the proof.

We next apply Proposition 3.3 to the variational inequality problem. Let $C$ be a nonempty, closed, and convex subset of a Hilbert space $H$ and let $A: C \rightarrow H$ be a singlevalued monotone operator which is hemicontinuous. Then a point $u \in C$ is said to be a solution of the variational inequality for $A$ if

$$
\langle y-u, A u\rangle \geq 0,
$$

for all $y \in C$. We denote by $\operatorname{VI}(C, A)$ the set of all solutions of the variational inequality (4.2) for $A$. We also denote by $N_{C}(x)$ the normal cone for $C$ at a point $x \in C$, that is,

$$
N_{C}(x)=\{z \in H:\langle y-x, z\rangle \leq 0 \text {, for all } y \in C\}
$$

Theorem 4.2 Let $C$ be a nonempty, closed, and convex subset of a Hilbert space $H$ and let $A: C \longrightarrow H$ be a single-valued monotone operator and hemicontinuous such that $\operatorname{VI}(C, A) \neq \emptyset$. Let $\left\{x_{n}\right\}$ be a sequence defined as follows:

$$
\left\{\begin{array}{l}
x_{0} \in H \\
y_{n}=\alpha_{n} \phi x_{n}+\left(1-\alpha_{n}\right) x_{n}, \\
x_{n+1}=V I\left(C, A+I-y_{n}\right)
\end{array}\right.
$$


for all $n \geq 0$, where $\left\{\alpha_{n}\right\}$ is a sequence of positive real numbers and $\phi \in \Sigma_{H}$. If the sequence $\left\{\alpha_{n}\right\}$ satisfies the conditions (C1)-(C2), then the sequence $\left\{x_{n}\right\}$ converges strongly to $x^{*}$ in $\operatorname{VI}(C, A)$.

Proof Define a mapping $T \subset H \times H$ by

$$
T x= \begin{cases}A x+N_{C}(x), & x \in C, \\ \emptyset, & x \notin C .\end{cases}
$$

By the Rockafellar theorem [27], we know that $T$ is maximal monotone and $T^{-1} 0=$ $V I(C, A)$.

Note that

$$
x_{n+1}=V I\left(C, A+I-y_{n}\right)
$$

if and only if

$$
\left\langle y-x_{n+1}, A x_{n+1}+x_{n+1}-y_{n}\right\rangle \geq 0,
$$

for all $y \in C$, that is,

$$
-A x_{n+1}-x_{n+1}+y_{n} \in N_{C}\left(x_{n+1}\right) .
$$

This implies that

$$
x_{n+1}=J^{T}\left(\alpha_{n} \phi x_{n}+\left(1-\alpha_{n}\right) x_{n}\right) .
$$

Using Corollary 3.9, $\left\{x_{n}\right\}$ converges strongly to an element $x^{*}$ in $V I(C, A)$. This completes the proof.

\section{Competing interests}

The authors declare that they have no competing interests.

\section{Authors' contributions}

All authors contributed equally and significantly in writing this article. All authors read and approved final manuscript.

\section{Author details}

${ }^{1}$ Department of Mathematics Education, Kyungnam University, Changwon, Gyeongnam 631-701, Korea. ${ }^{2}$ Department of Mathematics and Informatics, Thainguyen University, Thainguyen, Vietnam.

\section{Acknowledgements}

This work was supported by the Basic Science Research Program through the National Research Foundation Grant funded by Ministry of Education of the republic of Korea (2014046293)

Received: 6 October 2014 Accepted: 30 December 2014 Published online: 01 February 2015

\section{References}

1. Martinet, B: Regularisation d'inequations variationnelles par approximations successives. Rev. Fr. Inform. Rech. Oper. 4, 154-158 (1970)

2. Rockaffelar, RT: Monotone operators and proximal point algorithm. SIAM J. Control Optim. 14, $887-897$ (1976)

3. Güler, O: On the convergence of the proximal point algorithm for convex minimization. SIAM J. Control Optim. 29, 403-419 (1991) 
4. Bauschke, HH, Matoušková, E, Reich, S: Projection and proximal point methods convergence results and counterexamples. Nonlinear Anal. TMA 56, 715-738 (2004)

5. Lehdili, N, Moudafi, A: Combining the proximal algorithm and Tikhonov regularization. Optimization 37, 239-252 (1996)

6. Xu, H-K: A regularization method for the proximal point algorithm. J. Glob. Optim. 36, 115-125 (2006)

7. Song, Y, Yang, C: A note on a paper: A regularization method for the proximal point algorithm. J. Glob. Optim. 43, 171-174 (2009)

8. Tuyen, TM: A regularization proximal point algorithm for zeros of accretive operators in Banach spaces. Afr. Diaspora J. Math. 13, 62-73 (2012)

9. Kim, JK, Tuyen, TM: Regularization proximal point algorithm for finding a common fixed point of a finite family of nonexpansive mappings in Banach spaces. Fixed Point Theory Appl. 2011, 52 (2011)

10. Sahu, DR, Yao, JC: The prox-Tikhonov regularization method for the proximal point algorithm in Banach spaces. J. Glob. Optim. 51, 641-655 (2011)

11. Zegeye, $\mathrm{H}$, Shahzad, $\mathrm{N}$ : Strong convergence theorems for a common zero of a finite family of $m$-accretive mappings. Nonlinear Anal. TMA 66, 1161-1169 (2007)

12. Yao, Y, Liou, YC, Wong, MM, Yao, JC: Hierarchical convergence to the zero point of maximal monotone operators. Fixed Point Theory 13, 293-306 (2012)

13. Ceng, LC, Ansari, QH, Schaible, S, Yao, JC: Hybrid viscosity approximation method for zeros of $m$-accretive operators in Banach spaces. Numer. Funct. Anal. Optim. 32(11), 1127-1150 (2011)

14. Tuyen, TM: Strong convergence theorem for a common zero of $m$-accretive mappings in Banach spaces by viscosity approximation methods. Nonlinear Funct. Anal. Appl. 17, 187-197 (2012)

15. Witthayarat, U, Kim, JK, Kumam, P: A viscosity hybrid steepest-descent methods for a system of equilibrium problems and fixed point for an infinite family of strictly pseudo-contractive mappings. J. Inequal. Appl. 2012, 224 (2012)

16. Meir, A, Keeler, R: A theorem on contraction mappings. J. Math. Anal. Appl. 28, 326-329 (1969)

17. Suzuki, T: Moudafi's viscosity approximations with Meir-Keeler contractions. J. Math. Anal. Appl. 325, 342-352 (2007)

18. Goebel, K, Reich, S: Uniform Convexity, Hyperbolic Geometry and Nonexpansive Mappings. Dekker, New York (1984)

19. Ha, KS, Jung, JS: Strong convergence theorems for accretive operators in Banach space. J. Math. Anal. Appl. 147, 330-339 (1990)

20. Xu, H-K: Strong convergence of an iterative method for nonexpansive and accretive operators. J. Math. Anal. Appl. 314, 631-643 (2006)

21. Wong, NC, Sahu, DR, Yao, JC: Solving variational inequalities involving nonexpansive type mappings. Nonlinear Anal. TMA 69, 4732-4753 (2008)

22. Barbu, V, Precupanu, T: Convexity and Optimization in Banach Spaces. Editura Academiei R.S.R., Bucharest (1978)

23. Takahashi, W: Nonlinear Functional Analysis. Fixed Point Theory and Applications. Yokohama Publishers, Yokohama (2009)

24. Jung, JS: Strong convergence of an iterative method for finding common zeros of a finite family of accretive operators. Commun. Korean Math. Soc. 24(3), 381-393 (2009)

25. Rockafellar, RT: Characterization of the subdifferentials of convex functions. Pac. J. Math. 17, 497-510 (1966)

26. Jung, JS: Some results on Rockafellar-type iterative algorithms for zeros of accretive operators. J. Inequal. Appl. 2013, 255 (2013). doi:10.1186/1029-242X-2013-255

27. Rockafellar, RT: On the maximality of sums of nonlinear monotone operators. Trans. Am. Math. Soc. 149, 75-88 (1970)

\section{Submit your manuscript to a SpringerOpen ${ }^{\circ}$ journal and benefit from:}

- Convenient online submission

Rigorous peer review

- Immediate publication on acceptance

- Open access: articles freely available online

- High visibility within the field

- Retaining the copyright to your article 